\title{
Spontan İntraserebral Hematomların Cerrahi Tedavisi
}

\author{
Habibullah Dolgun ${ }^{1} \odot$, Şahin Hanalioğlu' ${ }^{1}$, Levent Gürses ${ }^{1} \oplus$, Gülce Gel' ${ }^{1}$,

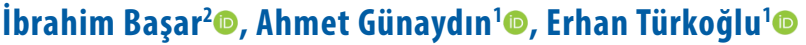

'Sağlık Bilimleri Üniversitesi Dışkapı Yıldırım Beyazıt Eğitim ve Araştırma Hastanesi, Beyin ve Sinir Cerrahisi Kliniği, Ankara, Türkiye ${ }^{2}$ Sağlık Bakanlığı Siirt Devlet Hastanesi, Beyin ve Sinir Cerrahisi Kliniği, Siirt, Türkiye

Habibullah Dolgun, Doç. Dr. Şahin Hanalioğlu, 0p. Dr. Levent Gürses, Op. Dr. Gülce Gel, Dr. İbrahim Başar, 0p. Dr. Ahmet Günaydın, 0p. Dr. Erhan Türkoğlu, Doç. Dr.

Illetişim:

Doç. Dr. Erhan Türkoğlu

Sağlık Bilimleri Üniversitesi Dışkapı Yıldırım Beyazıt Eğitim ve Araştırma Hastanesi, Beyin ve Sinir Cerrahisi Kliniği, Ankara, Türkiye Tel: +905056260200

E-Posta: drmet122@yahoo.com
ÖZET

Amaç: Bu çalışmanın amacı tüm inmelerin yaklaşık beşte birini oluşturan ve yüksek mortalite ve morbidite oranlarına sahip intraserebral hematomların (iSH) klinik-radyolojik özellikleri, cerrahi tedavi endikasyonları ve sonuçlarını geniş bir klinik seriden elde edilen tecrübeler ışı̆ında analiz etmektir.

Gereç ve Yöntem: Çalıșmaya 0cak 2006 - Aralık 2017 tarihleri arasında, spontan iSH nedeniyle kliniğimizde ameliyat edilen 18 yas üstü tüm hastalar dahil edildi. Hastaların epikriz kayıtları, radyolojik görüntüleri, ameliyat notları ve takip sonuçları retrospektif olarak incelendi. Yaş, cinsiyet, risk faktörü varlığı, başvuru anındaki nörolojik durum, hematomun lokalizasyonu ve hacmi, radyolojik özellikler, cerrahi teknik, postoperatif nörolojik sonuçlar, re-operasyon ve takip sonuçlarını içeren veriler toplandı.

Bulgular: Spontan ISH nedeniyle toplam 88 hasta $(30$ kadın $(\% 34,1), 58$ erkek $(\% 65,9))$ opere edildi. Tanı anındaki yaş ortalaması 59,3 $\pm 20,1$ yl (aralık: 18-97, ortanca: 62) olarak hesaplandı. Bașlıca başvuru semptom ve bulguları bilinç kaybı, bulantı-kusma, şiddetli baş ağıısı, ajitasyon, nöbet ve kuvvet kaybı (hemipleji) idi. Hastalar semptomların ortaya çıkışııı takiben 20 dakika ile 5 saat arasında değişen sürelerde acile başvurdu. 74 hastaya $(\% 84,1)$ dekompresif hemikraniyektomi + hematom aspirasyonu, 14 hastaya $(\% 15,9)$ kraniyotomi + hematom aspirasyonu uygulandı. Ventriküle açıımıs kanaması olan 58 hastanın $(\% 65,9) 22$ 'sinde (\%25) izlemde gelişen hidrosefali nedeniyle eksternal ventriküler drenaj (EVD) ihtiyacı oldu. Antiagregan/antikoagülan kullanımı olan $37(\% 42)$ hastanı 5 'inde $(\% 5,7)$ tekrarlayan kanama veya hematom boyutunda artış gözlendi. Hastaların 47 'si $(\% 53,4)$ kanamadan sonraki ilk 30 gün içinde hayatını kaybetti. GKS'si 8 ve daha düşük, kan hacmi ise $70 \mathrm{~cm} 3$ 'ün üzerinde olan hastalarda ise bu dönemde ölüm oranı \%88 olarak bulundu.

Sonuç: Antiagregan/antikoagülan kullanım öyküsü bulunan, yaşlı, hipertansif hastalarda daha yaygın görülen iSH mortalite ve morbiditesi oldukça yüksek bir hastalıktır. İleri yaş, çoklu yandaş hastalık varlığı, büyük hematom hacmi, başvuru anındaki düşük Glasgow koma skalası kötü prognoz ile ilişkilidir. Erken ve etkili cerrahi tedavi özellikle genç, yandaş hastalığı olmayan, nörolojik durumu nisbeten iyi veya ani kötüleşen hastalarda hayat kurtarııı olabilmektedir.

Anahtar sözcükler: Intraserebral hematom, hemorajik inme, cerrahi, dekompresyon, kraniyektomi

\section{SURGICAL TREATMENT OF SPONTANEOUS INTRACEREBRAL HEMATOMAS}

\section{ABSTRACT}

Objective: Intracerebral hematomas (ICH) comprise one-fifth of all strokes and is associated with high mortality and morbidity rates. We aimed to analyze the clinical-radiological features, surgical treatment indications and results of spontaneous ICH in a large clinical series from a single institution.

Materials and Methods: All patients who are older than 18 years of age and underwent surgery for spontaneous ICH between January 2006 and December 2017 were included. Patient charts, radiological images, operation notes and follow-up results were retrospectively evaluated. Data about age, sex, risk factors, neurological status at presentation, location and size of the hematoma, surgical technique, postoperative neurological outcomes, reoperation and follow-up results were collected.

Findings: A total of 88 patients ((30 female (34.1\%), 58 male (65.9\%)) were operated for spontaneous ICH. Mean age was $59.3 \pm 20.1$ years (range: 18-89, median: 62). The main symptoms and signs were loss of consciousness, nausea-vomiting, severe headache, agitation, seizure and motor weakness (hemiplegia). Patients were admitted at varying times from 20 minutes to 5 hours following the symptom onset. Decompressive hemicraniectomy + hematoma aspiration was performed in $74(84.1 \%)$ patients whereas 14 patients underwent craniotomy + hematoma aspiration. External ventricular drainage was required in 22 (25\%) of 58 patients (65.9\%) who had an intraventricular bleed. Recurrent bleeding or increased hematoma size was detected in 5 $(5.7 \%)$ of $37(42 \%)$ patients using antiaggregant/anticoagulant agents. Forty-seven $(53.4 \%)$ patients died within the first 30 days after bleeding. The 30-day mortality rate was $88 \%$ in patients with $\mathrm{GCS} \leq 8$ and blood volume $>70 \mathrm{~cm} 3$.

Conclusion: ICH is more common in elderly, hypertensive patients with a history of antiaggregant/anticoagulant use. The older age, multiple comorbid diseases, large hematoma volume, low GCS at presentation are associated with poor prognosis. An early and effective surgical treatment can be life-saving especially in patients who are young, have no comorbid disease and a relatively good neurological state or with a sudden worsening.

Keywords: intracerebral hematoma, hemorrhagic stroke, surgery, decompression, craniectomy
Gönderilme Tarihi : 09 Aralık 2018

Revizyon Tarihi : 18 Şubat 2019

Kabul Tarihi : : 05 Mart 2019 
nme, tüm dünyada mortalite ve morbiditenin en önde gelen nedenlerinden biridir $(1,2)$. Inmelerin ikinci en yaygın sebebi olan ve $\% 10-55$ arasında sıklık bildirilen spontan (non-travmatik) isH olguları, etkin tedavi şeması net bir şekilde ortaya konamamış, mortalitesi son derece yüksek (ilk bir aylık ölüm oranı \%30-50), gerek yüksek mortalite ve gerekse kalıcı morbidite nedeniyle toplumda önemli sosyo-ekonomik etkilere neden olan olgulardır (2-5). ISH ile ilgili çalışmalara literatürde, diğer inme ve intrakranial kanama nedenlerine göre daha az rastlanmaktadır (6). Sistemik hastalığa sahip, antiagregan/antikoagülan tedavi öyküsü bulunan ve ileri yaştaki hipertansif hastalar spontan ISH için riskli hastalardır. Spontan iSH'nin hipertansiyon dışında anevrizma, vasküler malformasyonlar, antitrombotik/antiagregan kullanımı veya koagülopatiler gibi birçok farklı sebebi vardır (7). Küçük boyutlu iSH'lerde konservatif/medikal tedavi ön plandayken, büyük hematom hacmi ve kötü nörolojik durum ile ilişkili iSH'ler erken ve agresif tedavi gerektirir. Hemorajik inmelerin ölüm oranı iskemik inmelere göre daha yüksektir ve mortal olmayan olgularda bile ciddi sekeller kalabilir. Hastaların sadece \%20'si intraserebral kanamadan altı ay sonra kimseye intiyaç duymadan hayatını sürdürebilmektedir $(5,8)$.

isH'de uygulanan tüm tedavi modalitelerindeki temel prensip, esasında hematomun ve aktif ozmotik proteinlerin neden olduğu perihematomal ödemin meydana getirdiği kitle etkisini ortadan kaldırmak ve/veya azaltmak, kafa içi basıncı düşürmek ve böylece beyin perfüzyonu ve oksijenizasyonunu normal hale getirmektir. Medikal tedaviden, minimal invazif endoskop destekli cerrahi ve geniş cerrahi kraniyektomiye kadar birçok tedavi bu amaçla günümüzde uygulanmaktadır $(3,9)$. Farklı tedavi şemalarının tercih edildiği spontan iSH'li hastalarda hematomun hacmi ve nörolojik kaybın derecesi, medikal tedaviyi içeren konservatif tedavinin mi yoksa cerrahi işlemin mi yapılacağını belirler (4).

Bu çalışmada amacımız, kliniğimizde cerrahi olarak tedavi edilen ISH olgularını analiz ederek, cerrahi tedavinin endikasyonlarını ve klinik sonuçlarını tartışmaktır.

\section{Gereç ve Yöntem}

Hasta popülasyonu

Bu retrospektif çalışma, Sağlık Bilimleri Üniversitesi Dışkapı Eğitim ve Araştırma Hastanesi Klinik Araştırmalar Etik Kurulu'nun 12/11/2018 tarih ve 56/13 nolu kararı ile onaylanmıştır. Ocak 2006-Aralık 2017 yılları arasını kapsayan 12 yıllık sürede Nöroşirürji Kliniği'nde 18 yaş ve üzerinde, klinik ve radyolojik olarak teyit edilmiş ve standart kraniyotomi veya dekompresif kraniyektomi + hematom aspirasyonu yapılan toplam 88 erişkin spontan isH olgusu çalışmaya dahil edildi. Cerrahi öncesi değerlendirmede tüm hastalarda hematom hacmi $30 \mathrm{~cm}^{3}$ ün üzerinde ve 5 mm'den fazla orta hat şifti ve/veya nörolojik kayıp (GKS $<9$ veya 2 puandan fazla düşüş) mevcuttu. Veriler retrospektif olarak hasta epikrizleri ve elektronik hasta kayıtları incelenerek elde edildi. Kontrole gelmemiş hastaların en son klinik bilgilerine telefon aracılığıyla ulaşıldı.

\section{Klinik ve radyolojik veriler}

Tüm hastalar acil servise başvurdu; klinik değerlendirmeyi takiben hemodinamik parametreler stabil olduktan sonra tüm hastalara beyin BT çekildi. İSH hacmi BT görüntüleri üzerinden $A \times B \times C / 2$ yöntemi kullanılarak hesaplandı. Hematom hacmi $30 \mathrm{~cm}^{3}$ ün üzerinde ve GKS $\leq 8$ olan 71 $(\% 80,7)$ hasta acil cerrahi için hazırlandı ve ameliyata alındı. Ayrıca başvuru sırasında GKS > 8 olan ancak izlemde kötüleşen veya maksimal optimal medikal tedaviye rağmen beklenen iyileşme göstermeyen hastalar da daha sonra cerrahiye alındı ve çalışmaya dahil edildi. Malign hastalık öyküsü, koagülasyon bozukluğu, hamilelik, tümör içi kanama, anevrizma, kavernom veya AVM gibi vasküler malformasyon kanamaları, komplike diabet mellitus, belirgin akciğer, karaciğer ve renal fonksiyon kaybı gibi ağır komorbideteye sahip olan ve GKS $\leq 4$ olan hastalar cerrahi için uygun hasta olarak kabul edilmedi ve çalışmaya alınmadı.

\section{Cerrahi prosedür ve prognostik faktörler}

Kanama parametrelerinde anormal değeri olan veya laboratuvar değerleri ile tespit edilemeyen antikoagülan kullanım öyküsü bulunan hastalar, gerekli önlemler alındıktan sonra veya kanama parametreleri düzeltildikten sonra cerrahiye alındı. Kanama başlangıcından itibaren ilk 12 saat içinde cerrahi uygulanan hastalar erken cerrahi olarak adlandırıldı. Cerrahi için hazırlanan hastalarda ISH tahliyesi için hematomun yerleşimine uygun geniş cilt insizyonu (sıklıkla travma flebi), standart kraniyotomi (sıklıkla hemikraniyektomi), dura açıışı, kortikotomi, hematom aspirasyonu, hemostaz, SF irrigasyon ve geniş duraplasti uygulandı. Dekompresif hemikraniyektominin bileşeni olarak uncusun rahatlatılabilmesi amacıyla yüksek hızlı drill yardımıyla sfenoid kanat tıraşlandı ve temporal kemik zigomatik arkusa kadar eksize edildi. Galeal greft duraplasti için kullanıldı; sıklıkla gevşek olarak normal dura kenarlarına süture edildi. Kraniyektomi boyutunun $10 \times 8 \mathrm{~cm}$ 'den küçük olmamasına ve kortikotominin hematoma en yakın ve güvenli yerden yapılmasına dikkat edildi. Hiçbir hastada hematoma ulaşma mesafesi 3 cm'nin üzerinde değildi. Beyin dokusu belirgin derecede 
rahatlamış olsa da 74 hastada $(\% 84,1)$ kemik greft hastanın abdominal bölgesinde cilt altına yerleştirildi (dekompresif hemikraniyektomi). On dört hastada $(\% 15,9)$ kemik greft yerine yerleştirildi (standart kraniyotomi). Hematom tahliyesi sonrası post-op dönemde yeniden kanama hastaların altısında $(\% 6,8)$ görüldü. Cerrahi sonrası hastalar yakın izlem amacıyla beyin cerrahi yoğun bakım ünitesine alındı. Ameliyat sonrası hemodinamik göstericileri stabil olan hastalara ameliyatı takip eden ilk 24 saat içinde erken post-op beyin BT çekildi. Hastaların sedasyon durumları, aldıkları medikal tedavi, günlük GKS ve nörolojik muayene notları kaydedildi. Taburculuğu gerçekleşen tüm hastalar hayatta kaldıkları süre boyunca takip edildi (Şekil 1).

Kanama anındaki yaş, cinsiyet, ilk nörolojik muayene (GKS), komorbidite, antiagregan/antikoagülan kullanımI, radyolojik bulgular (taraf, lokalizasyon, herniasyon, korteks ile ilişki ve kanama miktarı) ve ventrikül ile ilişkisi prognostik değişkenler olarak incelendi.

\section{Istatistiksel analiz}

İstatistiksel analiz için SPSS 22.0 (IBM, New York, ABD) programı kullanıldı. Normal dağııım gösteren parametrik veriler ortalama \pm standart sapma şeklinde, normal dağıIım göstermeyen parametrik veriler ve parametrik olmayan veriler ortanca (aralık) veya yüzde olarak sunuldu. İkili grup karşılaştırmalarında parametrik veriler için Student-t testi, parametrik olmayan sürekli değişkenler için MannWhitney $U$ testi, kategorik değişkenler içinse ki-kare testi kullanıldı. P değeri $<0,05$ istatistiksel olarak anlamlı kabul edildi.

\section{Bulgular}

Demografik, klinik ve cerrahi veriler

\section{Demografik özellikler}

Kliniğimizde 11 yıllık süre içinde ameliyat edilen 18 yaş ve üstünde 88 spontan İSH olgusu tespit edildi (Tablo 1). Ameliyat edilen olguların 58'i erkek $(\% 65,9), 30$ 'u kadın $(\% 34,1)$ hasta idi ve erkek/kadın oranı 1,9 idi. Opere edilen hastaların yedisi $(\% 8) 30$ yaş altında, 23'ü $(\% 26,1) 50$ yaş altındaydı. Başvuru anındaki hasta yaşı göz önüne alındığında yaş ortalaması $59,3 \pm 20,1$ yaş (18-89 yaş) olarak tespit edildi.

\section{Semptomlar ve klinik özellikler}

Hastaların tümü bilinç kaybı, şiddetli baş ağrısı ve/veya kusma, ajitasyon, kuvvet kaybı (hemipleji) veya nöbet gibi kafa içi basınç artışına bağı şikayetlerle başvurdu. Kanama anında antikoagülan ve/veya antiagregan kullanmaya devam eden 37 hasta (\%42) vardı. Ameliyat öncesi GKS ortalaması 7,8 $\pm 1,2$ (4-11 arası) idi. Post-op birinci, yedinci ve 15 günlerde GKS ortalaması sırasıyla 7,6 $\pm 1,1$ (5-12), $8,4 \pm 2,4$ (5-14) ve $10,2 \pm 2,8$ (4-15) idi.

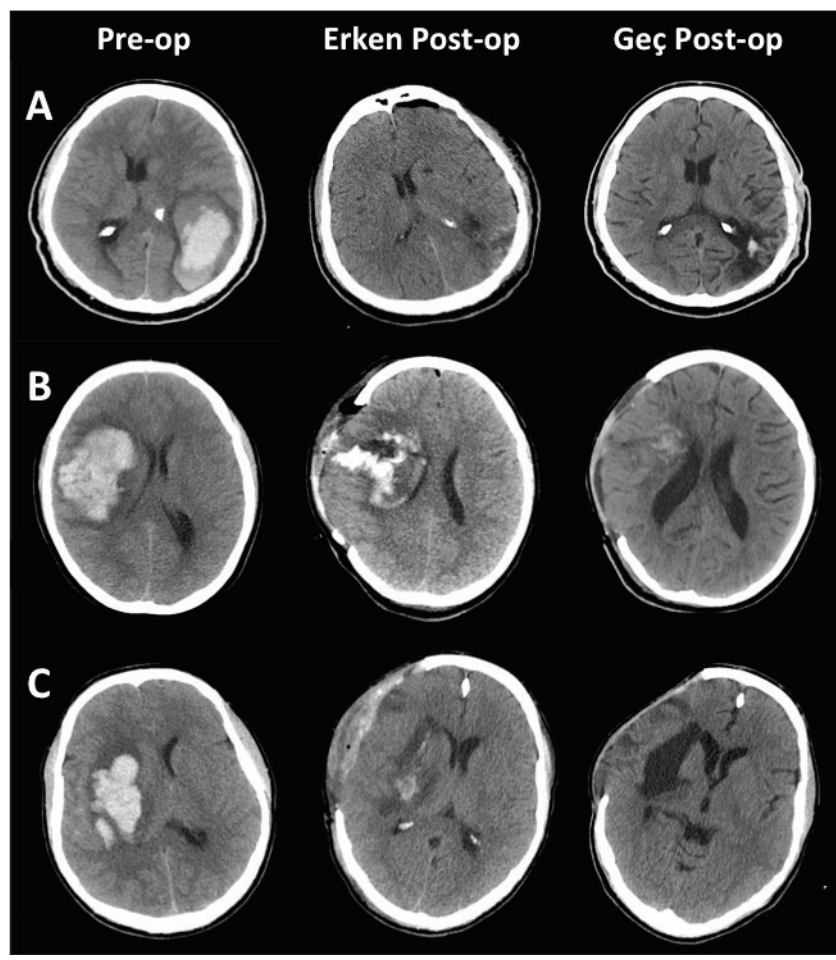

Sekil 1. Farklı yerleşimli ISH ile başvuran üç farklı hastaya ait ameliyat öncesi (pre-op), ameliyattan hemen sonra (erken post-op) ve ameliyattan yaklaşık 1,5-2 ay sonra (geç post-op) çekilen beyin bilgisayarlı tomografi (BT) görüntüleri.

Tablo 1. Hastaların demografik, klinik, radyolojik ve cerrahi özellikleri

\begin{tabular}{lcc} 
Yaş (yıl) & Ortalama \pm S.S. & $55.3 \pm 20.1$ \\
& Ortanca & 62 \\
& Aralık & $18-75$ \\
\hline & $<30$ yaş & $7(\% 8)$ \\
& $30-50$ yaş & $16(\% 18)$ \\
\hline Cinsiyet & $>50$ yaş & $65(\% 74)$ \\
\hline Antiagregan/ & Kadın & $30(\% 34.1)$ \\
Antikoagülan kullanımı & Erkek & $58(\% 65.9)$ \\
\hline Başvuru Şikayeti & Bilinç kaybı \pm bulant//kusma & $63(\% 71.6)$ \\
& Kuvvet kaybı (hemiparezi) & $55(\% 62.5)$ \\
& Şiddetli baş ağrısı/ajitasyon & $34(\% 38.6)$ \\
\hline Başvuru anında GKS & Nöbet & $12(\% 13.6)$ \\
\hline Lokalizasyon & GKS $\leq 8$ & $71(\% 80.7)$ \\
& GKS 9-12 & $11(\% 12.5)$ \\
& GKS $\geq 13$ & $6(\% 6.8)$ \\
\hline Cerrahi Iş̧lem & Lobar & $29(\% 32.9)$ \\
& Putaminal & $38(\% 43.2)$ \\
\hline Takip Sonuçları & Talamik & $21(\% 23.9)$ \\
\hline
\end{tabular}


Radyolojik karakteristikler ve hematom boyutları

İlk radyolojik değerlendirme olan beyin BT'lerde hematomun tipik özelliği olan hiperdens görünüm vardı.88 isH hastasının yaklaşık 1/3'ü (29 hasta $(\% 32,9))$ lobar, 38'i $(\% 43,2)$ putaminal, $21^{\prime} i(\% 23,9)$ ise talamik hematoma sahipti. Boşaltılan hematomun ortalama yüzdesi $\% 85$ idi ve tekrar kanama oranı \%9,1 idi. Beyin BT görüntülerinden elde edilen hacim hesaplarına göre hematom volümü $30-250 \mathrm{~cm}^{3}$ arası değişmekle birlikte ortalama $84 \mathrm{~cm}^{3}$ idi (ortanca $53 \mathrm{~cm}^{3}$ ). On yedi hastada $(\% 19,3)$ hematom miktarının $70 \mathrm{~cm}^{3}$ ün üzerinde olduğu tespit edildi. Kırk beş hastada $(\% 51,1)$ hematom sağ beyin yarısında yerleşmişti. Ventriküle açılmış kanama 58 olguda $(\% 65,9)$ mevcuttu. Bu olguların 32'sinde (tüm hastaların \%36,4'ü, lateral ventriküle açılmış hematoma sahip hastaların ise $\% 55,1$ i) ise kanamanın 3 . ve 4 . ventriküllere ulaştığı görüldü. Korteksle ilişkili kanaması olan dokuz hasta $(\% 10,2)$ vardı. Hastaların 56'sında $(\% 63,6) 5-10 \mathrm{~mm}$ arası değerde, 32 'sinde $(\% 36,4)$ ise $10 \mathrm{~mm}$ 'den fazla subfalsin herniasyon mevcuttu.

\section{Cerrahi sonuçlar ve ek tedavi modaliteleri}

73 hasta (\%83) ilk değerlendirme sonrası birinci saatte acil olarak ameliyata alındı. Acil cerrahi planı olmayan 15 hasta (\%17) yakın klinik ve radyolojik izlem amacıyla yoğun bakım ünitesine transfer edildi. 15 hastanın dördü $(\% 4,5)$ ilk 48 saat içinde medikal tedaviye beklenen yanıtı göstermediği, 11 hasta da $(\% 12,5)$ nörolojik gerileme ve/veya hematom miktarında radyolojik olarak artış tespit edildiği için daha sonra operasyona alındı. Ortalama operasyon süresi 110 dakika idi. Cerrahi öncesi ilk görüntülemesinde kan hacminin $70 \mathrm{~cm}^{3}$, ilk nörolojik muayenede ise GKS'nin $\leq 8$ olduğu hastalarda olumlu sonuç oranı yaklaşık \%12 idi (Modified Rankin Scale (mRS) $\geq 3$ olan hastalar).

\section{Takip sonuçları}

Hasta takip sonuçları cerrahi sonrası GKS ve mRS'nin esas alındığı nörolojik ve radyolojik değerlendirme temelinde altı aylık gözlem süresi üzerinden değerlendirildi. İlk bir haftalık izlemin sonunda ortalama GKS; 9,4 iken 6 . ayın sonunda bu skor 11,6'ya yükseldi. Başvuru GKS'si 8 ve altında olan 43 hastanın 19'u ilk bir haftanın sonunda hayatını kaybetti. Bu hastaların yedisi 50 yaşın altında idi. Illk ayın sonunda hayatını kaybeden 47 hastadan 29'unda (\%33) hematom ventriküle açılmıştı. İzlemin 6. ayında hayatını kaybeden hasta sayısı 56 olarak tespit edildi $(\% 63,6)$. Hayatta kalanların ise yaklaşık yarısında mRS ortalama 4,6 idi. İzlemin 6 . ayında sadece altı hasta $(6,8)$ destekle yürüyebildi ve belirgin bir iyileşme gösterdi. Sağkalımı üç haftanın üzerine çıkan hastalar bu sürenin sonunda yoğun bakım ünitesinden (YBÜ) palyatif servise transfer edildi. 24 hastaya $(\% 27,2)$ uzun süren entübasyon nedeniyle YBÜ'nden çıkarılmadan önce trakeostomi ve beslenme tüpü açıldı. Hastaların yaklaşık yarısında $(38$ hasta $(\% 43,2))$ yüksek ateş sonrası radyolojik ve mikrobiyolojik olarak akciğer enfeksiyonu tespit edildi. Uygun antibiyoterapi ile bu hastaların yine yarısına yakını düzelme gösterirken diğer yarısı kaybedildi. Dört hastada $(\% 4,5)$ yara yeri akıntısı gelişirken iki hasta menenjit $(\% 2,3)$ tedavisi aldı. Tekrar kanama izlenmeyen ve kanama parametreleri normale dönen tüm hastalara post-op 72. saatte enoksaparin (Cleaxene ${ }^{\circ}$ ) DVT proflaksisi olarak başlandı. İzlemde bir hasta $(\% 1,1)$ DVT'nin yol açtığı PTE nedeniyle kaybedildi.

\section{Tartışma}

Dünyanın en önde gelen mortalite ve morbidite nedenlerinden biri, hemorajik olgular başta olmak üzere inmelerdir $(1,2)$. Hemorajik inmeler iskemik olanlara göre çok daha ölümcül seyrettiği için erken, agresif ve etkin bir tedavi gerektirir. Bu, sağkalım ve düşük morbidite gereklilikleri açısından zorunludur. Geniş ve büyük hacimli isH'lerde kafa içi basınç artışı meydana gelirken, sağlıklı nöral dokular bası etkisi altında kalır. Serebral perfüzyon bozulur ve oksijen kaynakları beyin dokusuna etkin ve yeterli şekilde ulaşamaz. Bu olumsuz tabloya neden olan parenkimal şişliğin tek sebebi hematomun kitle etkisi değildir. Şişliğe ve bası bulgularına katkı sağlayan ve aktif ozmotik proteinlerin çevre nöral dokular üzerinde meydana getirdiği etkinin bir sonucu olarak kanamaya sekonder gelişen perihematomal ödem, (10-14) kitle etkisinin yanında ilk 24 saat içinde progresyon gösterir ve çevre dokularda ek hasara yol açar $(7,12,15)$. Böylece sekonder hasarı meydana getiren kaskad aktifleşmiş olur. Illerleyen süreçte hayati fonksiyonları yöneten merkezlere serebral herniasyon gerçekleşir ve ölüm riski doğar.

Bu olgularda kötü klinik seyri önleyebilecek veya minimize edebilecek medikal ve/veya cerrahi tedavilerin yapıldığı randomize karşılaştırmalı çalışmalarda dramatik bir gelişme henüz kaydedilememiştir. Nöroşirürjikal müdahalenin tartışmalı olduğu isH olgularında cerrahi uygulamalar, tam bir tedavi şeması gözetilmeksizin devam etmektedir $(4,16,17)$. Hematom boşaltımı olmaksızın dekompressif kraniyektomi, hematom boşaltımına eşlik eden kraniyotomi ve hematom boşaltılmasının eşlik ettiği dekompressif kraniyektomiden stereotaktik ve endoskopik minimal invazif hematom aspirasyon yöntemlerine kadar bir çok farklı cerrahi prosedür isH hastalarında uygulanabilmektedir. 


\section{Cerrahinin rolü ve etkinliği}

Kanamanın tetiklediği bir dizi mekanizmayla bozulan otogerülasyon ve cerrahi işlemin kafa içi basınç artışını (KIBA) yeterli derecede düşürememesi fayda ve etkinliğin arzu edilen düzeyde ortaya çıkamamasına neden olabilir (3, 18). Etkin ve başarılı bir cerrahi yapılsa dahi ilk saatlerde düşen KIBA ilerleyen saatlerde tekrar yükselebilmektedir. Bu nedenle kanamanın cerrahi olarak aspirasyonu ve/veya dekompresif kraniyektomi, sağkalım oranları açısından her zaman yeterli olamamaktadır. Özellikle geniş hacimli ve vakaların yaklaşık yarısına yakınını meydana getiren (\%42-53) ventriküle açılmış kanamalarda hayatta kalma oranı ilk bir ayda çok daha düşüktür $(3,4,19)$. Bu durum göz önüne alındığında, akut ISH olgularında cerrahi işlemin rolü ve etkinliği hakkında tam bir fikir birliğinin oluşamamasının gerekçesi ortaya çıkmaktadır $(3,10)$. Yine de literatürde geniş spontan hemisferik kanamaya sahip hastalarda, uygulandığında faydalı olduğuna dair kanıtlar bulunan dekompresif hemikraniyektomi (DHK) oldukça yaygın kullanıı (3). Cerrahi tahliyenin etkinliğinin yetersiz olduğunu savunan çalışmaların aksine iSH hastalarında mortalite oranının daha düşük olduğunu vurgulayan veriler oldukça sıktır (5, 20, 21). Özellikle GKS'si 8 ve daha düşük, kan hacmi ise 60 $\mathrm{cm}^{3}$ ün üzerinde olan hastalara cerrahi önerilmektedir (3).

Hematom boşaltımı olmaksızın tek başına DHK çok ilgi uyandırmamıştır (7). Böyle olmakla birlikte supratentorial iSH hastalarında hematom boşaltımı olmaksızın büyük dekompresif kraniyektomiyi değerlendiren çalışmalar da vardır (7, 22-25). Kraniyotomi + hematom boşaltılması ile dekompresif hemikranektomi + hematom boşaltılmasını karşılaştıran çalışmalar dekompresyonun etkin rol oynadığını düşündürmektedir (7). Dekompresif kraniyektomili hastalar ile konservatif yöntemlerle tedavi edilen hastalar arasındaki karşılaştırmalar sonucunda DHK'nin supratentoryal kanamalı hastalar için yararlı etkileri olduğunu göstermiştir. Fung ve ark. yaptıkları çalışmada hematom boşaltımı olmaksızın DHK ile tedavi edilen 12 hastadan üçü (\%25), konservatif tedavi alan 15 hastanın ise sekizi (\%53) hayatını kaybetmiş̧ir (23). Benzer bir şekilde 2015 yılında Esquenazi Y. ve ark.'nın hematom tahliyesi olmaksızın DHK'li hastaları dâhil ettiği çalışmasında 3 ayın sonunda \%55 hastada olumsuz sonuç vardı (25). Rasras ve ark. ise çalışmalarında, hematom tahliyesi olmaksızın DHK'li hastalardaki altı aylık ölüm oranını yaklaşık \%27 olarak verirken bu oran hematom tahliyesi ile birlikte kraniyotomi yapılan hastalarda yaklaşık \%14 olarak tespit edilmiştir.

\section{Cerrahi komplikasyonlar}

Kanama sonrası bozulan otoregülasyon, perihematomal ödem etkisi, sekonder hasar, kortikotomi ve ekartmanın olumsuz sonuçları, hidrosefali, enfeksiyon riski gibi konularda henüz yeterli çalışma yoktur. Özellikle ventriküle açılmış kanaması olan ve takibinde menejit, ventrikülit benzeri enfeksiyonlar gelişen cerrahi uygulanmış hastalarda, travmatik beyin hasarlı hasta verileri ile uyumlu olacak şekilde hidrosefali her beş hastanın birinde, ateş yüksekliği ve enfeksiyon bulguları ise $\% 3$ oranında karşımıza çıkmaktadır (3, 26-28). Bizim çalışmamıza ait veriler de bu oranlarla benzerlik göstermektedir (menenjit: \%2,3, hidrosefali: \%6).

\section{Cerrahi ve medikal tedavinin karşılaştırılması}

Ölüm riskini azaltmak ve hastaya fayda sağlamak için alternatif bir tedavi metodu olan dekompresif hemikranektomi (DHK), KIBA'yı azaltmak, beyin herniasyonunu önlemek ve sağlıklı nöral dokulardaki basıyı ortadan kaldırmak veya minimize etmek için kafatasından bir kemik flebin çıkarıldığı, şiş olan beynin dışarı doğru çıkmasına izin veren bir cerrahi prosedürdür (29). Serebral kompliansı artırdığ gibi, serebral kan akımını da artııır ve nöral dokulara oksijen temin edilmesinde iyileşme sağlar. Ayrıca radyolojik görüntülerde de düzelme meydana getirir (30-32). Malign orta serebral arter tıkanıklığında intrakranial basıncı düşürürken prognozun iyileşmesini sağlar ancak bahsedilen bu olumlu sonuç bir başka SVO çeşidi olan ISH'li hastalar için net bir şekilde ortaya konamamıştır (7). Son çalışmalar İSH'de cerrahinin etkin ve faydalı olduğunu destekler veriler sunmaktadır. Bazı hastalarda fonksiyonel olarak bozulmuş, ancak iSH çevresinde potansiyel olarak yaşayabilir doku olan bir penumbra meydana gelir. Pıhtıların cerrahi olarak çıkarılması, bu penumbra alanının fonksiyonlarında iyileşme sağlar (33). Faydalı etkilerinin yanında parenkim için zararlı olabilecek etkileri de barındıran bir işlem olan kortikotomiyi gerektirdiği için ise tüm literatürde kabul gördüğü söylenemez. Literatürde derin yerleşimli kanamalarda hematom aspirasyonu olmaksızın DHK'nin hematom aspirasyonu + DHK'ye denk geldiğini savunan çalışmalar bildirilmiş ve kortikotomi gibi zararlı etkileri olabilecek bir işlemin yapılmaması ve hematom boşlatılmasında harcanan zamandan kazanım bir avantaj olarak vurgulanmıştır (7). Ayrıca hematomun tahliyesi sırasında kullanılan ekartörün, sağlıklı dokulara bası etkisi ile venöz drenajı bozup ödem miktarında artışa sebep olmasının yanısıra, değerli kortikal alanları etkileyen olumsuz sonuçları da göz önünde bulundurulmalıdır. Bahsedilen bu riskler nöroşirürjiyenler için cerrahiye karar verme aşamasında bir zorluk oluşturabilir. Ancak tüm risklere rağmen cerrahi tahliyenin iyi sonuçlar verdiğine ait verilerin paylaşılması bu alanda ilgiyi artırmış ve içinde bulunduğumuz son 10 yılda bu konuda birçok çalışma yayımlanmıştır. 


\section{DHK ile DHK + hematom boşaltılmasının karşılaştırılması}

Rasras ve ark.'nın 2014-2016 yıllarını kapsayan, prospektif olarak gerçekleştirdiği ve 30 hastanın dahil edildiği çaış̧masında 13 hastaya hematom boşaltılması olmaksızın dekompresif hemikraniyektomi gerçekleştirildiği, diğer 17 hastaya ise hematom boşlatılması + dekompresif hemikraniyektomi yapıldığı bildirilmiştir (7). Aynı çalışmada altı aylık bir izlem sonunda bu iki grup arasında mortalite ve GKS verileri açısından istatistiksel olarak anlamlı fark bulunmamıştır $(P>0,05)(7)$. Ancak aynı çalışmada Rasras ve ark. $\mathrm{GKS}=4-5$ olan hastalarda hematom boşaltma işleminin yalnızca DHK yapılan hastalara göre bir miktar daha iyi sonuç doğurduğunu da vurgulamıştır (hematom boşaltılması yapılan hastalarda \%35,3, sadece DHK yapılanlarda \%30,7) (7).

\section{Minimal invazif cerrahi aspirasyon}

Endoskopik ve stereotaktik minimal invaziv yöntemlerle hematom aspirasyonu, genel durumu iyi ve hematom miktarı küçük olgularda güvenli, etkin ve iyi sonuçlar verebilir (34). Dar çalışma alanı, hem hemostaz için zorluk teşkil eder hem de yeniden kanama riski oluşturur (9). Hui-Tzung Luh, 2017 yılında yayımladığı makalesinde endoskop yardımı ile gerçekleştirdiği hematom boşaltılmasının geleneksel kraniyektomiden daha etkili ve daha güvenli olduğunu bildirmektedir (9). Ancak minimal invaziv yöntemler kan hacmi $40 \mathrm{~cm}^{3}$ ün üzerinde olan geniş hematomlar ve GKS'si 8 ve altında olan hastalar için uygun değildir (kan hacmi $25-40 \mathrm{~cm}^{3}$ ve GKS'si 9 ve üzeri olmaIıdır) (34).

Hematom hacmi-ventrikül ilişkisi -sağkalım ve mortalite oranları

Broderick ve ark.'nın kan hacminin $60 \mathrm{~cm}^{3}$ ün üzerinde ve GKS $\leq 8$ olan hastaların sadece $\% 16$ 'sında cerrahinin gerçekleştirildiği toplam 142 hasta ile yaptığı çalışmada ilk bir aydaki mortalite oranı \%91 olarak bulundu (35). Bu oran tümünde cerrahi uygulanan 88 hasta ile gerçekleştirdiğimiz çalışmamızda $\left(70 \mathrm{~cm}^{3}\right.$ ün üzerinde kan hacmine sahip hastalarda) \%88 idi. Morbidite oranları açısından incelendiğinde ise $40-45 \mathrm{~cm}^{3}$ den daha fazla hacme sahip isH'lerde ciddi morbidite oranı \%96-97'lere ulaşmaktadır $(7,10,11,36)$. Mortalitenin \%13 gibi çok düşük değerlerde olduğu çalışmalar olsa da bu düşük değerin hastalardaki kan hacminin göreceli olarak az olmasına ve yüksek GKS değerlerine bağlı olduğu düşünülmektedir (hastaların sadece \%30'unda GKS $\leq 8$ idi) (22). Küçük hacimli kanamalarda ilk planda medikal yöntemler önerilirken orta ve büyük boyutlara ulaşan hematomlarda hangi tedavinin etkin, faydalı ve güvenli olduğu konusu hala net bir bilgi yoktur $(5,37)$. Cerrahinin konservatif tedaviye üstün olmadığını savunan çalışmalar da literatürde mevcuttur
$(19,38,39)$. Aksine kapsamlı bir çalışma olan Surgical Trial in Intracerebral Hemorrhage (STICH) 2 çalışması ile Mendelow konservatif tedavi ile erken cerrahinin hasta sonuçları üzerindeki etkileri belirlemeye çalışmış, ventriküle açılmayan lobar hematoma sahip hastaların cerrahi drenajdan fayda gördüklerine dair kanıtlar sunmuştur (4). Satoru ve ark.'nın çalışması cerrahi uygulanan hastalarda olumlu sonuçları \%41, mortalite oranını ise $\% 28$ olarak bildirmiştir (3). Bu sonuçlar uygun hastalarda hematom aspirasyonu ve DHK'nin ne kadar etkin, faydalı ve gerekli olduğuna dair önemli bir kanıt sunar. Ayrıca ölüm oranının daha yüksek olduğu ve oranın $\% 53$ olarak ifade edildiği ventriküle açılmış hematomu olan hastalarda bile cerrahinin olumlu etkileri aynı çalışmada gösterilmiştir.

\section{Erken cerrahinin önemi}

Zamanlama ile ilgili belirleyici veriler olamamakla birlikte çalışmamızda erken cerrahi uygulamanın ölüm oranını göreceli olarak azalttığı ve mevcut olumlu sonuçların temel nedeni olduğu düşünülmektedir. Literatürde erken cerrahi grup olarak nitelenen hastaların ilk 24 ve 30 saat içinde ameliyata alındığı $(3,19)$ bizim çalışmamızda ise bu sürenin yaklaşık 12 saat olduğu gözlenmiştir. Cerrahi öncesi GKS'si 9 ve üzerinde olan hastaların altı aylık izlem sonunda sonuçlarının daha iyi olduğu gözlendi.

\section{Risk faktörleri ve prognoz}

Ameliyat sonuçları ve prognozu ön görmeyi sağlayan en temel veri hastanın başvuru sırasındaki bilinç durumunu içeren nörolojik tablosu ve hematom miktarıdır. ISH'li hastada etkin bir tedavi yönetimi ortaya koyabilmek için hastanın acil olarak değerlendirilip tanının konulması şartının yanında, kanamanın ventriküle açılıp açılmadığı ve kanama nedeni de göz önünde bulundurulmalıdır. Kan basıncı ve kan şekeri kontrolü, kanama parametrelerindeki bozukluk, cerrahi hemostaz, nöbet proflaksisi, hipo/ hipertermi, gelişmesi muhtemel iskemik hasar ve yeniden kanama da tedavinin etkinliğinde göz önünde sıkı bir şekilde takip edilmelidir. İSH'lerin prognozunu inceleyen sınırlı sayıda çalışma vardır. Feng Yan ve ark.'nın 2018 yılında yayınladıkları ve altı yıllık tecrübenin paylaşıldığı, 1187 olgunun dahil edildiği, temelde ISH hastalarındaki prognozun incelendiği çalışmada diabetin bir aylık, 65 yaş üstü olmanın ise beş yıllık ölüm oranlarını etkileyen bağımsız risk faktörü (independent predictor) olduğu bildirilmiş, kanamanın ventriküle açılması ve/veya beyin sapına kanama varlığının ise hem kısa hem uzun süreli mortalite oranlarının bağımsız belirleyicisi olduğu vurgulanmıştır (1). Aynı çalışmada Feng yan, bir ayın sonunda hayatına devam eden hastalardaki nüks kanama oranını $\% 32,5$ olarak tespit etmiştir. 
Gregson ve ark.'nın gerçekleştirdiği bir meta-analizde GKS ve hematom hacmi ele alınmış ve prognoz açısından sonuçların çok yüz güldürücü olamadığı, olumlu sonuçların GKS $\leq 8$ olan hastalarda $\% 5$, hematom hacimleri $80 \mathrm{~cm}^{3}$ veya daha fazla olan hastalarda ise sadece $\% 7$ olarak belirtilmiştir (40).

isH'li bir olguda amaçlanan en temel sonuç, tedavinin hiç kimseye bağımlı kalmakasızın hastanın hayatını kendine yeter bir şekilde devam ettirebileceği iyi prognozu sağlayabilmektir. Bunun sağlanması için başarılı bir cerrahi tek başına yeterli değildir. Başarılı bir hematom boşaltılması sonrası klinik ve labaratuvar bulguları yakından takip edilmeli, kaliteli bir beslenmeyi de içeren etkin bir sağlık hizmeti verilmelidir.

Son zamanlarda iSH hastalarındaki sağkalımı artırıcı ve morbiditeyi azaltıcı çalışmalara olan ilginin artarak devam ettiğini görmekteyiz. Sayıları her geçen gün artan bu çalışmaların önümüzdeki zaman dilimi içinde ümit verici sonuçlar elde edeceği öngörülmektedir.

ISH'lerin yönetiminde henüz net bir tedavi şemanın ortaya konulamaması, literatürde bir fikir birliğinin oluşmaması geniş hasta serilerini içeren çalışmaları bu alanda zorunlu kılmaktadır.

\section{Kaynaklar}

1. Yan F, Yi Z, Hua Y, Shen Y, Li M, Ding Y, et al. Predictors of mortality and recurrent stroke within five years of intracerebral hemorrhage. Neurol Res 2018;40:466-72. [CrossRef]

2. Yang G, Wang Y, Zeng Y, Gao GF, Liang X, Zhou M, et al. Rapid health transition in China, 1990-2010: findings from the global burden of disease study 2010. Lancet 2013;381:1987-2015. [CrossRef]

3. Takeuchi S, Wada K, Nagatani K, Otani N, Mori K. Decompressive hemicraniectomy for spontaneous intracerebral hemorrhage. Neurosurg Focus 2013;34:E5. [CrossRef]

4. Mendelow AD, Gregson BA, Mitchell PM, Murray GD, Rowan EN, Gholkar AR, the STICH II Investigators. Surgical trial in lobar intracerebral haemorrhage (STICH II) protocol. Trials 2011;12:124. [CrossRef]

5. Bhaskar MK, Kumar R, Ojha B, Singh SK, Verma N, Verma R, et al. A randomized controlled study of operative versus nonoperative treatment for large spontaneous supratentorial intracerebral hemorrhage. Neurol India 2017;65:752-8. [CrossRef]

6. Hemphill JC 3rd, Greenberg SM, Anderson CS, Becker K, Bendok BR, Cushman M, et al. Guidelines for the Management of Spontaneous Intracerebral Hemorrhage: A Guideline for Healthcare Professionals from the American Heart Association/American Stroke Association. Stroke 2015;46:2032-60. [CrossRef]

7. Rasras S, Safari H, Zeinali $M$, Jahangiri $M$. Decompressive hemicraniectomy without clot evacuation in supratentorial deep-seated intracerebral hemorrhage. Clin Neurol Neurosurg 2018;174:1-6. [CrossRef]

8. Counsell C, Boonyakarnkul S, Dennis M, Sandercock P, Bamford J, Burn J, Warlow C. Primary intracerebral haemorrhage in the Oxfordshire community stroke project 2 prognosis. Cerebrovasc Dis 1995;5:26-34. [CrossRef]
Toplam 88 hastayı kapsayan bu tek merkezli çalışmadan edindiğimiz deneyime dayanarak cerrahi işlem uyguladığımız spontan ISH hastalarının klinik-radyolojik davranışları, potansiyel prognostik karakteristikleri, risk faktörleri ile ilişkisi, tedavi stratejileri, ve takip sonuçlarının yanında DHK'nin etkinlik ve güvenilirliğini incelemek ve tartışmak amacıyla bu çalışmayı planladık. Ayrıca çalışmamız hedefe yönelik tedavi için bir şema ortaya koymak amacıyla var olan önerilere bir katkı da sunmaktadır.

\section{Sonuç}

Prognostik faktörler göz önüne alındığında, diabet ve hipertansif kalp hastalığı gibi komorbiditeye sahip ileri yaştaki kadın hastalarda prognoz daha kötüdür. Her hasta için prognostik göstericiler de göz önünde bulundurularak en etkin tedavi şeması ortaya konmalıdır. Böylece sağlık hizmetleri ve sosyal hizmetler alanında kalite artmış ve maliyetler düşmüş olacaktır. Hastalar için mümkün olan en kaliteli bakımı sağlamak, risk faktörlerinin iyi anlaşılması ve etkin bir tedavi şemasının ortaya konması şartına bağlıdır. Ancak bulguların doğruluğunu net bir şekilde doğrulamak için büyük, prospektif, randomize çalışmalara intiyaç vardır.

9. Luh HT, Huang APH, Yang SH, Chen CM, Cho DY, Chen CC, et al. Local hemostatic matrix for endoscope-assisted removal of intracerebral hemorrhage is safe and effective. J Formos Med Assoc 2018;117:6370. [CrossRef]

10. Brouwers HB, Goldstein JN. Therapeutic strategies in acute intracerebral hemorrhage. Neurotherapeutics 2012;9:87-98. [CrossRef]

11. Hanggi D, Steiger HJ. Spontaneous intracerebral haemorrhage in adults: a literature overview. Acta Neurochir (Wien) 2008;150:371-9, discussion 9. [CrossRef]

12. Balami JS, Buchan AM. Complications of intracerebral haemorrhage. Lancet Neurol 2012;11:101-18. [CrossRef]

13. Lo Presti MA, Bruce SS, Camacho E, Kunchala S, Dubois BG, Bruce E, et al. Hematoma volume as the major determinant of outcomes after intracerebral hemorrhage. J Neurol Sci 2014;345:3-7. [CrossRef]

14. Zheng JS, Yang F, Xu QS, Yu JB, Tang LL. Treatment of hypertensive intracerebral hemorrhage through keyhole Transsylvian approach. J Craniofac Surg 2010;21:1210-2. [CrossRef]

15. Kirkman MA, Smith M. Supratentorial intracerebral hemorrhage: a review of the underlying pathophysiology and its relevance for multimodality neuromonitoring in neurointensive care. J Neurosurg Anesthesiol 2013;25:228-39. [CrossRef]

16. Fernandes $H M$, Mendelow AD. Spontaneous intracerebral haemorrhage: a surgical dilemma. Br J Neurosurg 1999;13:389-94. [CrossRef]

17. Gregson BA, Mendelow AD, for STICH Investigators. International variations in surgical practice for spontaneous intracerebral haemorrhage. Stroke 2003;34:2593-8. [CrossRef]

18. Maira G, Anile C, Colosimo C, Rossi GF. Surgical treatment of primary supratentorial intracerebral hemorrhage in stuporous and comatose patients. Neurol Res 2002;24:54-60. [CrossRef] 
19. Mendelow AD, Gregson BA, Fernandes HM, Murray GD, Teasdale GM, Hope DT, et al. Early surgery versus initial conservative treatment in patients with spontaneous supratentorial intracerebral haematomas in the International Surgical Trial in Intracerebral Haemorrhage (STICH): a randomised trial. Lancet 2005;365:387-397. [CrossRef]

20. Miller CM, Vespa P, Saver JL, Kidwell CS, Carmichael ST, Alger J, et al. Image-guided endoscopic evacuation of spontaneous intracerebral hemorrhage. Surg Neurol 2008;69:441-6. [CrossRef]

21. Juvela S, Heiskanen O, Poranen A, Valtonen S, Kourne T, Kaste M, Troupp $\mathrm{H}$. The treatment of spontaneous intracerebral hemorrhage: A prospective randomized trial of surgical and conservative treatment. J Neurosurg 1989;70:755-8. [CrossRef]

22. Ramnarayan R, Anto D, Anilkumar TV, Nayar R. Decompressive hemicraniectomy in large putaminal hematomas: an Indian experience. J Stroke Cerebrovasc Dis 2009;18:1-10. [CrossRef]

23. Fung $C$, Murek $M, Z^{\prime}$ Graggen WJ, Krähenbühl AK, Gautschi OP, Schucht $P$, et al. Decompressive hemicraniectomy in patients with supratentorial intracerebral hemorrhage. Stroke 2012;43:3207-11. [CrossRef]

24. Heuts SG, Bruce SS, Zacharia BE, Hickman ZL, Kellner CP, Sussman ES, et al. Decompressive hemicraniectomy without clot evacuation in dominant-sided intracerebral hemorrhage with ICP crisis. Neurosurg Focus 2013;34:E4. [CrossRef]

25. Esquenazi Y, Savitz S, Khoury RE, McIntosh MA, Grotta JC, Tandon N. Decompressive hemicraniectomy with or without clot evacuation forlarge spontaneous supratentorial intracerebral hemorrhages. Clin Neurol Neurosurg 2015;128:117-22. [CrossRef]

26. De Bonis P, Pompucci A, Mangiola A, Rigante L, Anile C. Posttraumatic hydrocephalus after decompressive craniectomy: an underestimated risk factor. J Neurotrauma 2010;27:1965-70. [CrossRef]

27. Kim KT, Park JK, Kang SG, Cho KS, Yoo DS, Jang DK, et al. Comparison of the effect of decompressive craniectomy on different neurosurgical diseases. Acta Neurochir (Wien) 2009;151:21-30. [CrossRef]

28. Yang XF, Wen L, Shen F, Li G, Lou R, Liu WG, Zhan RY. Surgical complications secondary to decompressive craniectomy in patients with a head injury: a series of 108 consecutive cases. Acta Neurochir (Wien) 2008;150:1241-8. [CrossRef]

29. Honeybul S, Ho KM. The current role of decompressive craniectomy in the management of neurological emergencies. Brain Inj 2013;27:979-91. [CrossRef]
30. Aarabi B, Hesdorffer DC, Ahn ES, Aresco C, Scalea TM, Eisenberg HM. Outcome following decompressive craniectomy for malignant swelling due to severe head injury. J Neurosurg 2006;104:469-79. [CrossRef]

31. Kontopoulos V, Foroglou N, Patsalas J, Magras J, Foroglou G, Yiannakou-Pephtoulidou $M$, et al. Decompressive craniectomy for the management of patients with refractory hypertension: should it be reconsidered? Acta Neurochir (Wien) 2002;144:791-6. [CrossRef]

32. Schaller B, Graf R, Sanada Y, Rosner G, Wienhard K, Heiss WD. Hemodynamic and metabolic effects of decompressive hemicraniectomy in normal brain. An experimental PET study in cats. Brain Res 2003;982:31-7. [CrossRef]

33. Siddique MS, Fernandes HM, Wooldridge TD, Fenwick JD, Slomka $\mathrm{P}$, Mendelow AD. Reversible ischemia around intracerebral hemorrhage: a single-photon emission computerized tomography study. J Neurosurg 2002;96:736-41. [CrossRef]

34. Zhou X, Chen J, Li Q, Ren G, Yao G, Liu M, et al. Minimally invasive surgery for spontaneous supratentorial intracerebral hemorrhage: a meta-analysis of randomized controlled trials. Stroke 2012;43:292330. [CrossRef]

35. Broderick JP, Brott TG, Duldner JE, Tomsick T, Huster G. Volume of intracerebral hemorrhage. A powerful and easy-touse predictor of 30-day mortality. Stroke 1993;24:987-93. [CrossRef]

36. Elijovich L, Patel PV, Hemphill J. Intracerebral hemorrhage. Semin Neurol 2008;28:657-67. [CrossRef]

37. Morgenstern LB, Frankowski RF, Shedden P, Pasteur W, Grotta JC. Surgical treatment for intracerebral hemorrhage (STICH): A singlecenter, randomized clinical trial. Neurology 1998;51:1359-63. [CrossRef]

38. Fernandes HM, Gregson B, Siddique S, Mendelow AD. Surgery in intracerebral hemorrhage: the uncertainty continues. Stroke 2000;31:2511-6. [CrossRef]

39. Mitchell P, Gregson BA, Vindlacheruvu RR, Mendelow AD. Surgical options inICH including decompressive craniectomy. J Neurol Sci 2007;261:89-98. [CrossRef]

40. Gregson BA, Broderick JP, Auer LM, Batjer H, Chen XC, Juvela S, et al. Individual patient data subgroup meta-analysis of surgery for spontaneous supratentorial intracerebral hemorrhage. Stroke 2012;43:1496-504. [CrossRef] 